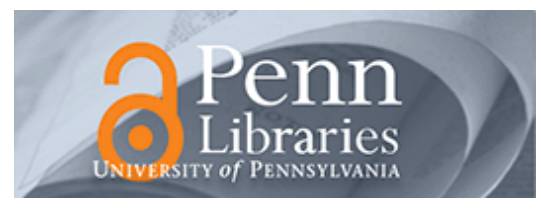

University of Pennsylvania

ScholarlyCommons

\title{
Accumulating a Portfolio of Experience: The Effect of Focal and Related Experience on Surgeon Performance
}

Diwas Singh Kc

University of Pennsylvania

Bradly R. Staats

Follow this and additional works at: https://repository.upenn.edu/oid_papers

Part of the Business Administration, Management, and Operations Commons, Health and Medical Administration Commons, and the Policy History, Theory, and Methods Commons

\section{Recommended Citation}

Kc, D., \& Staats, B. R. (2012). Accumulating a Portfolio of Experience: The Effect of Focal and Related Experience on Surgeon Performance. Manufacturing \& Service Operations Management, 14 (4), 618-633. http://dx.doi.org/10.1287/msom.1120.0385

This paper is posted at ScholarlyCommons. https://repository.upenn.edu/oid_papers/130

For more information, please contact repository@pobox.upenn.edu. 


\title{
Accumulating a Portfolio of Experience: The Effect of Focal and Related Experience on Surgeon Performance
}

\begin{abstract}
One key driver of improvement in surgical outcomes is a surgeon's prior experience. However, research notes that not all experience provides equal value for performance. How, then, should surgeons accumulate experience to improve quality outcomes? In this paper, we investigate the differential effects of focal and related (i.e., tasks similar to, but not identical to, the focal task) experience. We open up the black box of the volume-outcome relationship by going beyond just dividing experience into focal and related categories, but also considering how subtasks and context (i.e., the organization in which the work takes place) affect performance. To understand these issues, we assemble a novel data set on 71 cardiothoracic surgeons who performed more than 6,500 procedures during a period of 10 years after the introduction of a breakthrough surgical procedure. We find that, as compared to related experience, surgeon focal experience has a greater effect on surgeon performance. We also demonstrate that subtask experience has different, nonlinear performance relationships for focal and related experience. Finally, we find that focal experience is more firm specific than related experience and that nonfirm experience reduces the learning rate for both focal and related experience. We discuss implications of our findings for healthcare delivery and operations management.
\end{abstract}

\section{Keywords}

healthcare, knowledge work, learning, quality, specialization, variety

\section{Disciplines}

Business Administration, Management, and Operations | Health and Medical Administration | Policy History, Theory, and Methods 


\title{
Accumulating a Portfolio of Experience: The Effect of Focal and Related Experience on Surgeon Performance
}

\author{
Diwas KC* \\ Emory University \\ 1300 Clifton Road NE \\ Atlanta, GA 30322 \\ Tel: 404-727-1424 \\ Fax: 404-727-6313 \\ diwas_kc@bus.emory.edu \\ Bradley R. Staats \\ University of North Carolina at Chapel Hill \\ Campus Box 3490, McColl Building \\ Chapel Hill, NC 27599-3490 \\ Tel: 919-962-7343 \\ Fax: 919-962-6949 \\ bstaats@unc.edu
}

December 2011

* Corresponding Author

\section{Acknowledgments}

We thank Rob Huckman, Gary Pisano, the associate editor, and the anonymous reviewers for helpful comments on earlier drafts of this paper. All errors remain our own. 


\section{Accumulating a Portfolio of Experience: The Effect of Focal and Related Experience on Surgeon Performance}

One key driver of improvement in surgical outcomes is a surgeon's prior experience. However, research notes that not all experience provides equal value for performance. How then should surgeons accumulate experience to improve quality outcomes? In this paper we investigate the differential effects of focal and related (i.e., tasks similar to, but not identical to, the focal task) experience. We open up the black box of the volume-outcome relationship by going beyond just dividing experience into focal and related categories, but also considering how sub-tasks, and context (i.e., the organization in which the work takes place) affect performance. To understand these issues, we assemble a novel data set on 71 cardiothoracic surgeons who performed over 6,500 procedures during a period of 10 years since the introduction of a breakthrough surgical procedure. We find that as compared to related experience, surgeon focal experience has a greater effect on surgeon performance. We also demonstrate that sub-task experience has different, non-linear performance relationships for focal and related experience. Finally, we find that focal experience is more firm-specific than related experience and that non-firm experience reduces the learning rate for both focal and related experience. We discuss implications of our findings for healthcare delivery and operations management.

Key Words: Healthcare, Knowledge Work, Learning, Quality, Specialization, Variety

\section{Introduction}

Research examining surgical outcomes in healthcare consistently finds significant variation across surgeons and hospitals (Hannan et al. 1990; Birkmeyer and Dimick 2009). Understanding the sources of variation and their impact on delivery of care is of significant interest to policy makers and researchers (Kaiser 2011). In this paper, we examine an important driver of outcome variation - physician cumulative volume (Sosa et al. 1998; Birkmeyer et al. 2003; Hammond et al. 2003; Waldman, Yourstone and Smith 2003; Vickers et al. 2007; Ramdas et al. 2010). With increasing surgeon volume, patient outcomes improve; however not all units of experience equally impact performance improvement (Mishina 1999; Lapré and Nembhard 2010; Argote and Miron-Spektor 2011). How then should surgeons accumulate volume in order to improve surgical outcomes? In this paper, we examine one knowledge-based and highly critical set of procedures - cardiac surgery - to answer this question (Novick and Stitt 1999; Pisano, Bohmer and Edmondson 2001; Anagnostopoulos et al. 2003).

Work in operations management has examined experience accumulation by separating 
task experience into two components: focal ${ }^{1}$ and related experience (i.e., tasks similar to, but not identical to, the focal task, Boh, Slaughter and Espinosa 2007; Narayanan, Balasubramanian and Swaminathan 2009; Staats and Gino 2011). As a first step, we investigate this division of individual task experience in health care (Huckman and Zinner 2008; Ramdas et al. 2010; KC and Terwiesch 2011). As noted by De Leval (1997), "Cardiac surgery shares many similarities with high-hazard enterprises, such as the aerospace industry, nuclear power plants, and chemical process plants (p. 724)." Therefore, it is necessary to investigate how different types of individual experience aid performance in such an uncertain and dynamic environment.

However, to understand how experience accumulation affects variation in surgical outcomes requires more than just dividing prior experience into focal and related categories. To look inside the "black box" of experience accumulation, we do the following:

First, we examine both focal and related experience at a more granular level in order to make a distinction between the sub-tasks being completed. For example, the class of minimally invasive cardiac surgeries (which serve as focal experience in our paper) includes a set of procedures that differ in the number and types of vessels that are bypassed. This kind of sub-task variety might aid the development of expertise by providing improved knowledge about the underlying relationships (Clark 1985; Bohn 2005). Alternatively, such variety might overwhelm an individual's cognitive resources and limit her ability to solve problems (Allport, Styles and Hsieh 1994; Sarason and Pierce 1996). Our analysis shows that focal and related sub-task varieties have opposite, non-linear effects on outcome.

Second, focal and related experience can be accumulated across different contexts. In the case of surgery this means that surgeons can complete their work at one or multiple hospitals. Huckman and Pisano (2006) find that in cardiac surgery, individual surgeon performance is firmspecific. Working repeatedly with the same organizational-specific assets, such as team members (Huckman, Staats and Upton 2009; Huckman and Staats 2011) results in improved performance. However, given the difference in knowledge that is gained from focal and related tasks, the two types of experience may transfer differentially across contexts. Further, firm-specific and nonfirm-specific experience (in both the focal and related categories) may interact to affect surgical performance. In other words, experience gained elsewhere may help to speed up, or slow down

\footnotetext{
${ }^{1}$ In this paper we refer to experience with the same task as "focal experience" while we refer to the act of repeatedly executing focal experience as "specialization."
} 
an individual's learning curve at a given firm.

To answer these questions, we examine the introduction of a new process technology within healthcare: minimally invasive cardiac surgery (Friedrich, Bonatti and Dapunt 1997). Learning curve studies of individuals in field settings often investigate contexts in which workers have executed a task many times before the study begins. By the time researchers begin data collection, much of the learning has already taken place. To circumvent this challenge, we examine a novel procedure that was introduced toward the beginning of the study period. We assemble a unique data set on 71 cardiothoracic surgeons who perform over 6,500 procedures over a period of 10 years. We therefore capture a significant portion of learning for all the individual surgeons in our chosen market.

In examining the portfolio of experience that surgeons should accumulate we contribute to both the operations management and health care literatures. First, we investigate the specialization and variety discussion in healthcare, at the individual level. Second, in examining sub-task type we find different, non-linear effects within focal and related experience. Third, by separating focal and related experience across organizational contexts we find that focal experience exhibits greater firm-specificity than does related experience. Further, we find that surgeons' rate of learning from experience at the present organization is decreasing in the volume of experience they have from other organizations (or said another way, the interaction effect between same-firm experience and other firm experience is related to worse performance for both focal and related experience).

Our findings have important managerial and healthcare policy implications. The positive relationship between surgeon experience and outcome is a key driver of the regionalization of care - the concentration of procedures at facilities in a region (Birkmeyer and Dimick 2009). Our results not only support this idea, since regionalization could increase firm-specific experience, but also highlight the need to allocate task in such a context more carefully (e.g., in terms of subtask variety). Our findings also offer suggestions for task allocation in hospitals, even those not part of a regionalization of care effort. Given that all experiences do not contribute equally to improving outcomes, selecting the mix of procedure types (based on both focal and related tasks as well as sub-task variety), can play an important role in improving surgeon performance. Finally, our findings suggest that when evaluating providers, patients should seek information on a surgeon's entire portfolio of surgeries, rather than just examining a surgeon's total volume and 
outcome.

\section{Setting}

This study examines cardiothoracic surgeons who conduct a class of minimally invasive cardiac procedures known as off-pump coronary artery bypass. This procedure was developed as an alternative to the traditional coronary artery bypass graft $(\mathrm{CABG})$ that was started in the late 1960's. A typical candidate for CABG surgery has varying degrees of blockage in one or more arteries supplying oxygenated blood to the heart muscle. The resultant lack of blood flow can greatly impede heart function and increase risk of a myocardial infarction (heart attack). In a CABG surgery, part of the donor vein from a leg or an artery from the chest is grafted onto the heart to bypass the blockage in the clogged vessel and restore blood flow to and from the heart muscle. The procedure is invasive: a surgeon splits the patient's breastbone and separates the ribs to gain access to the heart. A perfusionist then starts the cardiopulmonary bypass using a heartlung machine. Specifically, the machine takes on the role of the patient's heart during surgery, providing oxygenated blood to the rest of the body. Once cardiopulmonary bypass is established, the surgeon instructs the perfusionist to deliver cardioplegia, a special potassium mixture that stops the heart and slows its metabolism. Usually the patient's machine-circulated blood is cooled to around $84^{\circ} \mathrm{F}\left(29^{\circ} \mathrm{C}\right)$. The surgeon then begins the process of revascularization, i.e. attaching the graft onto the donor site and restoring circulation pathways to the heart muscle. Once the ends of each graft are sewn onto the coronary arteries, the heart is restarted.

Although CABG has benefited numerous patients, certain side effects are associated with the trauma of stopping and restarting a heart. In particular, patients undergoing a CABG are at heightened risk of neurological complications such as stroke, as well as increased risk of depression and overall physiological functioning (Roach et al. 1996; Puskas et al. 1998). To circumvent these issues, in the late 1990s an innovative new CABG procedure known as offpump CABG was developed. This procedure consists of performing bypasses with donor grafts on the beating heart, obviating the need for a perfusionist and a heart-lung machine. This procedure falls under the classification of minimally invasive cardiac procedures, and in the rest of the paper, we will refer to this type of procedure as minimally invasive. ${ }^{2}$ Although the risks

\footnotetext{
${ }^{2}$ The other type of minimally invasive cardiac procedure includes an incision on the side of the chest, instead of the breastbone (sternotomy) but still requires cardiopulmonary bypass, therefore this volume is captured in our other experience measure.
} 
associated with cardiopulmonary bypass (and stopping and restarting the heart) are removed, this procedure introduces other sources of complexity. In particular, a surgeon is required to perform the procedure on a beating heart, calling for additional dexterity and surgical skill.

Such a setting is appropriate for our analysis for several reasons. First, learning is a key process. Cardiothoracic surgeons are highly trained individuals (usually receiving not only four years of medical school training, but also seven years of residency and fellowship training). They represent a quintessential twenty-first century knowledge worker, and thus CABG has received significant attention in the management literature (e.g., Pisano et al. 2001; Huckman 2003; Huckman and Pisano 2006). Second, since we examine minimally invasive cardiac surgery shortly after the procedure was rolled out on the market, we are able to examine the introduction of a novel process and also view each individual surgeon's nearly complete history.

A third reason for using this setting is that cardiothoracic surgeons execute both traditional $\mathrm{CABG}$ and minimally invasive $\mathrm{CABG}$. Thus, we are able to observe workers completing related, but different, tasks. Fourth, there are different procedure types within both CABG and minimally invasive $\mathrm{CABG}$ and so we are able to identify sub-task variety. Fifth, surgeons may move between hospitals permitting us to examine the firm-specificity of prior experience. Sixth, risk-adjusted mortality is well established as an outcome measure for this procedure, used by the clinical literature in healthcare, and surgeon outcomes vary significantly, thus presenting opportunity to examine factors that may improve individual performance. Finally, cardiac care is a high-volume and high-revenue service sector, accounting for one-third of the entire patient volume in the U.S. and over a third of all Medicare spending (AHA 2008). This sheer economic importance and its impact on public health alone make this setting worthy of extensive research.

\section{Hypothesis Development}

\subsection{Focal and Related Experience at the Individual Level}

Whether tasks should be allocated in a specialized or varied manner has been a topic of constant focus in operations management (Taylor 1911; Skinner 1985). Specialization may improve individual performance for several reasons. With repeated experience, an individual gains knowledge about the task and, in so doing, learns about relationships between the processes that 
make up the task as well as the processes' underlying causal linkages (Bohn 2005; Bohn and Lapré 2011). This increased understanding creates opportunity for an individual to both improve individual parts of the task and to redesign the entire process (Adler et al. 2009). Work examining individual expertise finds that competence in a skill can require hundreds of hours (Anderson 1982), and mastery can require many years (Chase and Simon 1973). Healthcare research finds that learn-how activities (steps to operationalize a practice) relate to new process implementation success, while learn-what activities (steps to identify best practice) do not (Tucker, Nembhard and Edmondson 2007). Given its potential for deep and careful analysis, specialization may offer the best opportunity to gain learn-how knowledge (Ramdas et al. 2010).

Specialization is also valuable as it limits worker distractions due to task change (Schultz, McClain and Thomas 2003; Staats and Gino 2011). Psychology research shows that when a worker switches to a different task it is necessary to load the steps to complete the task into her working memory (Rubinstein, Meyer and Evans 2001). Laboratory studies find that when subjects switch between cognitive-intensive tasks, they may experience information overload and see performance degrade (Allport et al. 1994; Speier, Valacich and Vessey 1999). Further, individuals must apply cognitive resources to inhibit the stimuli from prior tasks, and so those resources are not available for the present task (Wylie and Allport 2000). Thus, specialization may aid learning by limiting cognitive interference (Sarason and Pierce 1996). ${ }^{3}$

While specialization offers a number of learning benefits, recent work suggests that variety in task experience may enhance the rate of learning (Schilling et al. 2003). Completing multiple, related tasks offers a number of potential benefits. First, knowledge transfer is possible as a solution for one task may be relevant but previously unused for another task (Hargadon and Sutton 1997). Second, when completing multiple tasks, an individual may identify higher-level principles that affect both tasks. As a problem-solver maps characteristics of the two problem domains, she recognizes linkages that not only allow her to transfer solutions from one area to the other, but also permit her to solve problems in new and unexpected ways (Gick and Holyoak 1980). This is consistent with work in innovation that finds novel solutions often require the

\footnotetext{
${ }^{3}$ This paper concentrates on specialization at the level of an individual worker. A stream of research examines specialization at the plant or organizational level - describing specialization with the term "focus" (Skinner 1974). Empirical work in this tradition typically finds benefits from focused operations (Lapré and Tsikriktsis 2006; Tsikriktsis 2007) — but not always (MacDuffie, Sethuraman and Fisher 1996). Recent work on focus at the operating-unit level investigates different types of focus and the role of related activities on operating performance (KC and Terwiesch 2011; Clark and Huckman 2011).
} 
connecting of knowledge that was previously thought unrelated (Fleming 2001). In addition to facilitating the transfer of knowledge and solutions across problem domains, related experience might also help to build competence in the skill of learning itself (Ellis 1965).

Executing different tasks may also provide motivational benefits (Herzberg 1966; Hackman and Oldham 1976). When executing the same task repeatedly, an individual may disengage or alternatively decide her present performance is acceptable and thus halt improvement efforts (Hackman 1969; Imai 1986). By switching between different tasks, an individual may not execute the same routine without thinking, but rather stay in a state of mindful learning (Levinthal and Rerup 2006).

While both focal and related experiences likely aid performance, the question is which is more beneficial for surgeons? For two reasons, we expect focal experience to dominate related experience. Our context, a new procedure in cardiac surgery, is quite different from prior studies that have examined more routine work environments such as software maintenance or data entry. The high pressure and high stakes of the surgical context necessitate reconsidering the phenomenon in this new environment. First, given the stakes involved (i.e., a patient's life) the increase in motivation from variety is likely to be less salient than in the case of routine work. In other words, variety may not significantly improve a surgeon's level of focus and motivation, as compared to specialization. Second given the task complexity and novelty of the surgical process, the direct knowledge gained from focal experience is likely to be more applicable to the focal task and hence more valuable. Said differently, it is easy to develop mastery over simple tasks quickly; once this is achieved, related tasks may prove more beneficial in generating greater total experience, and in turn improving focal task performance. However, for a complex procedure that requires significantly more time for mastery, such as the type that we study, related tasks are unlikely to offer comparable learning opportunities. Thus, we hypothesize:

HYPOTHESIS 1: A surgeon's focal experience is related to a larger improvement in surgical outcome than is a surgeon's related experience.

\subsection{Sub-task Variety}

Work on specialization and variety has typically defined relatedness by considering the current task as a focal task and all other tasks as variety. Examples include software modules (Boh et al. 2007; Narayanan et al. 2009), computer games (Schilling et al. 2003), and data entry 
stages (Staats and Gino 2011). However, outside of the realm of either very simple tasks or experiments run in the laboratory under tight control conditions, a real-world task consists of many sub-tasks. For example, within the class of minimally invasive cardiac procedures, there are differences in the number of vessels that are bypassed, and in whether a valve was repaired or replaced during the operation. We refer to this type of within-task variety as sub-task variety. In examining the performance effects of focal and related experience it is necessary to consider not only the overall experience effects, but also the impact of experience gained in sub-tasks.

Sub-task variety within focal experience might aid learning and performance. The concept of design hierarchies helps to explain why (Simon 1962; Clark 1985). Clark (1985) notes that technical progression occurs when a high-level architecture is set and then gradually lower-levels of the architecture are improved (Abernathy and Utterback 1978). For example, once the internal combustion engine was chosen as the platform to power a car, subsequent effort could be expended on lower-level design choices - the number of cylinders to use and how to configure the cylinders (Clark 1985). The same process can occur in a surgical context. If the focal task is minimally invasive cardiac procedures then a surgeon must first learn the high-level processes necessary to complete the surgery successfully (e.g., working without a pump). Once the surgeon has mastered the general process then she can seek to improve on aspects of surgeries that may differ across sub-tasks (e.g., when bypassing two vessels she need not follow all of the process steps to bypass vessel one and then repeat them to bypass vessel two, but instead start to combine some steps).

As both examples highlight, once the problem domain is defined (e.g., a minimally invasive cardiac surgery) then a problem solver can use variety in that domain to explore the search space in order to improve performance (Bohn and Lapré 2011). In other words, inside the realm of the focal task, exploration of different sub-task types helps a problem solver gain additional knowledge about the focal task by learning about the focal tasks' underlying causal linkages (Bohn 2005). Such experience may help an individual to recognize solutions in one area that apply to other sub-task types (Hargadon and Sutton 1997) and may also help a problem solver to develop higher order principles that improve performance in all sub-task types.

While some focal sub-task variety may aid performance, in excess, it may eventually harm performance. Putting knowledge gained from variety to use requires cognitive data processing as well as potential changes to one's practice and routine. With too much variety an 
individual may experience information overload (Johnson and Hasher 1987) or may expend effort on unsuccessful and counterproductive new routines. Similarly, with excessive variety an individual may be unable to test hypotheses effectively and identify patterns to improve understanding as too many variables are changing at once. Thus, we hypothesize:

HYPOTHESIS 2: $\quad$ A surgeon's focal sub-task variety exhibits an inverse U-shaped relationship with surgical outcomes whereby increasing values are first related to an improved surgical outcome and later to a worsening surgical outcome.

Next we examine the relationship between related sub-task variety and performance. Fundamentally the question is whether an individual benefits from a narrow subset of related experience or more "varied" related experience. While we hypothesize that focal sub-task variety will initially improve surgical outcome, we posit the opposite for related sub-task variety; limited sub-task variety may be preferable to moderate sub-task variety.

In the case of focal, sub-task variety the additional canvassing of the search space may be useful, at least up to a point, since all search is taking place within the focal domain. On the other hand, limiting the sub-task variety of related tasks may prove valuable for several reasons. First, although some related sub-task variety may help a surgeon understand the related task in more detail, not all of the additional understanding will be transferable to the focal task. By itself, that may not be problematic. However, the problem may arise due to a substitution in learning in the related task, as opposed to learning in the focal task. Namely, with increasing related sub-task variety individuals must devote valuable cognitive resources to understand how these pieces fit together for the related task. That means that those cognitive resources are unavailable for reflection and subsequent learning in the focal task.

Second, when an individual repeatedly executes a task she develops a cognitive representation of the task known as a task set. Changing tasks at hand necessitates changing the primary task set in her working memory (Monsell 2003). Prior work finds that there is an absolute cost to task change because individuals must go through a cognitive setup to prepare to execute the next task (Schultz et al. 2003; Staats and Gino 2011). More importantly, prior task sets may have an ongoing negative effect on performance (Allport et al. 1994; Allport and Wylie 1999). One cause of this ongoing detrimental effect is the expenditure of cognitive resources 
required to inhibit prior task sets (Waszak, Hommel and Allport 2003). Therefore, with increasing related sub-task variety, there are more task sets at play, and hence the need for greater cognitive resources to inhibit irrelevant task sets when completing the focal task.

Third, an additional challenge may come from a phenomenon called priming - when individuals learn to not only develop task sets for a particular scenario, but also to invoke a given task set when they encounter a stimulus for that specific scenario (Monsell 2003; Waszak, Hommel and Allport 2005). This cognitive process is helpful when the invoked task set is appropriate. However, increasing related sub-task variety may be associated with a growing number of task sets that are then automatically retrieved when an individual encounters a similar stimulus (i.e., executing the focal task). Given that these task sets may be irrelevant or even counterproductive to the focal task, this may worsen performance. ${ }^{4}$

While low sub-task variety may be preferable to moderate sub-task variety, it is possible that high sub-task variety will also dominate moderate sub-task variety. While increasing related sub-task variety may impede performance due to challenges in cognitive processing, experimental research suggests that individuals eventually learn to manage their varied task sets better. In particular, with increasing experience individuals may create task shells that include not only the elements of the task sets, but also a strategy for managing them together (Navon and Gopher 1979; Gopher, Armony and Greenshpan 2000). With the creation of a task shell fewer cognitive resources are needed to process related sub-task variety and so those resources can be allocated to learning in the focal task. Further, with a task shell in place less cognitive resources may be necessary to inhibit each task set. Thus, if task shells grow more prevalent at greater levels of variety then the cost of such variety may lessen. Altogether, this may lessen the negative performance impact of increasing related sub-task variety (though not necessarily to the level of zero related sub-task variety). Thus, we hypothesize that:

HYPOTHESIS 3: A surgeon's related sub-task variety exhibits a U-shaped relationship with surgical outcome whereby increasing values are first related to a worsening surgical outcome and later to an improving outcome.

\footnotetext{
${ }^{4}$ In contrast, priming with focal sub-task variety is less likely to be harmful for performance since each task set is associated with the actual task being completed. In fact such priming may even be helpful for performance (at least up to the point where a problem solver is overloaded)
} 


\subsection{Focal and Related Experience and Firm Specificity}

Finally, we consider one additional dimension upon which focal and related experience may differentially affect individual performance - firm specificity (or in the context of our paper, hospital-specificity). Huckman and Pisano (2006) find that individual surgeon performance is firm-specific. That is, prior experience within the focal hospital has a greater benefit for performance, as compared to experience at other hospitals. Their work builds on prior research that finds that learning often depends on the organizational context (Edmondson 2002). Huckman and Pisano (2006) suggest that familiarity with organizational-specific assets, such as team members, may be a key driver of firm-specificity. In particular, individuals who repeatedly work together grow more adept at identifying, sharing, and using one another's valuable knowledge (Edmondson et al. 2003; Huckman et al. 2009; Staats 2011).

The first question of interest for our paper is whether firm-specificity exists for both focal and related experience. When a surgeon executes any task at a hospital she gains knowledge about the task and develops familiarity with the organizational-specific assets, processes and routines, and with personnel such as the nurses, anesthesiologists, and residents. When considering any differences in firm-specificity across focal and related tasks, the question becomes how the task and familiarity components contribute to the total learning for each task type. We posit that learning from familiarity will be greater in focal, rather than related experience and therefore the firm-specificity of focal experience will be greater than that of related experience.

In order to arrive at this conclusion, we first consider individual level general surgical skills (e.g. her hand-eye coordination, clinical know-how, ability to deal with rare events). Experience with both related and focal tasks can improve a surgeon's general level of skill. For example, her incision and suturing skills, ability to generate quality grafts, and accuracy of her hand-eye coordination can improve with more time in the operating room. Such time can be gained at any organization's operating room. Therefore, we do not expect the general surgical skills to be firm specific.

On the other hand, familiarity with assets, processes and personnel is likely to be firm specific. However, familiarity gained from a related task plays a relatively less important role during a focal task. For example, familiarity with the heart-lung machine, experience on a set of routines for a radically different procedure, or prior work experience with a perfusionist, will not 
likely help with a minimally invasive surgical procedure (since these steps are not a part of a minimally invasive $\mathrm{CABG}$ ). This knowledge of assets, process and personnel is unhelpful, regardless of the organization where the related task was performed. Conversely, familiarity with assets, processes and personnel gained from a focal task can be brought to bear on any other focal task at the same firm. This effect is likely heightened when examining novel procedures, such as the minimally invasive procedures examined in our study. In novel settings, team member familiarity may be even more important as the team is learning to create new surgical protocols (Edmondson, Bohmer and Pisano 2001; Edmondson et al. 2003). In contrast, protocols for a coronary artery bypass graft $(\mathrm{CABG})$ or other older (related) procedures are more wellestablished across hospitals.

Altogether this suggests that firm-specificity will be greater in focal experience than with related experience. A strong form of the hypothesis would predict that focal experience will exhibit firm-specificity, while related experience will not.

HYPOTHESIS 4: $\quad$ A surgeon's focal experience will exhibit greater firm specificity in surgical outcome than the surgeon's related experience.

Finally, we examine if focal (or related) experience at one hospital and focal (or related) experience at other hospitals have a joint effect on performance. It is possible that firm-specific and non-firm-specific experience might have a complementary effect on performance. When working across organizations an individual may identify best practice in one context and apply it to another (Tucker et al. 2007). With this increased understanding each additional unit of firmspecific experience (either focal or related) may yield further performance improvement.

Conversely the joint effect may be detrimental for performance. With increasing volume of experience at other hospitals a surgeon learns the routines and practices of that hospital. However, since two hospitals are rarely identical in their approach (e.g. at a minimum the people are different) switching hospitals requires discovering that "this is not how we do things over here," learning the new processes, becoming familiar with a different cultural work environment, and gaining familiarity with surgical equipment potentially produced by a different vendor. Devoting cognitive resources to unlearning, mental and physical setup costs of switching to a new work environment, or at a minimum suppressing prior knowledge may reduce performance 
(Sarason and Pierce 1996; Monsell 2003).

Although we expect to see a positive performance relationship from the main effect for both focal and related experience gained at other hospitals, we postulate that the joint effect for focal and related experience on performance will be negative. We argue that given the extent of organization-level change required to implement best practices, it is unlikely that an individual doctor will be able to effectuate organizational change (through best practice transfer) in a way that results in faster learning. However, the distracting effects of experience from other firms are likely salient in most cases. Therefore, we hypothesize:

HYPOTHESIS 5: A surgeon's firm-specific focal experience and non-firm-specific focal experience interact to have a detrimental relationship with surgical outcome.

HYPOTHESIS 6: $\quad$ A surgeon's firm-specific related experience and non-firm-specific related experience interact to have a detrimental relationship with surgical outcome.

\section{Data and Empirical Strategy}

\subsection{Data}

Our data set consists of all cardiac procedures performed in the state of Massachusetts between October 1999 and September 2009. This includes information on a total of 6,516 minimally invasive procedures performed by 71 cardiac surgeons over the 10 -year period. Our surgical outcome variable or quality measure is the 30-day in-hospital postoperative mortality rate, which is the most widely used metric for benchmarking the performance of surgeons and institutions that perform cardiac surgery (Luft et al. 1990; Novick and Stitt 1999; Huckman and Pisano 2006). Therefore, in our empirical models a negative coefficient is related to a decrease in the likelihood of mortality and therefore an improved surgical outcome.

Several patient-level factors are known to impact surgical outcomes, including demographic variables such as age, gender, and race. Pre-existing co-morbidities (or accompanying clinical risk) such as incidence of diabetes and poor functioning bodily organs, are also known to significantly determine outcomes (Nashef et al. 2002). In addition to 
influencing outcome, these risks pose various challenges for the surgeon and delivery of care. Our analysis therefore includes these patient-level factors, which are listed in Table A-1 in the Appendix. Table 1 provides summary statistics for the non-categorical variables. We see that the average age of a patient undergoing a minimally invasive cardiac procedure is 68 years. The majority of patients have at least one accompanying clinical risk (e.g., cerebrovascular disease, neurologic or pulmonary risk, diabetes).

Since individual surgeon-level heterogeneity, such as reputation and training, could significantly impact surgeon performance, we obtain the encrypted surgeon identifier and the unique patient-surgeon pairs in our analysis. Specifically, we observe the patient controls, the surgeon who operated on the patient, the level of experience the surgeon had accumulated by the time they performed the surgery, and the outcome of the surgery. These variables permit us to estimate individual surgeon learning curves to test our six hypotheses.

In general, accurately estimating the effect of an individual worker's experience on performance is challenging for two reasons. First, perfecting a highly specialized task like a minimally invasive surgical procedure takes years. Learning therefore occurs over a long time horizon, and an accurate estimation of individual learning curves often calls for a long panel of observations. Second, one ideally would estimate learning curves early in the process, when the greatest learning is likely to occur. In other words, data collection would ideally start at when the surgeon starts to perform the procedure. Since the most significant of the minimally invasive procedures were introduced in 1998 (Gardner 2001), and we observe procedures beginning in October 1999 for a period of 120 months, our data is comprehensive enough to estimate most individuals' entire learning curves. ${ }^{5}$ Because we include the surgeon identifier in our analysis, our estimates examine the effect of cumulative volume at the individual surgeon level.

We dissect experience along several dimensions in order to test our hypotheses. First, given that we examine the outcomes for patients undergoing minimally invasive cardiac procedures, we define a surgeon's focal experience as the cumulative volume of minimally invasive cardiac surgeries that the surgeon has performed. Within the class of minimally invasive procedures, there are a number of different types of surgeries, which vary in the number of arteries that are bypassed, and whether a valve was repaired or replaced at the same time as the

\footnotetext{
${ }^{5}$ As noted by Lapré and Tsikriktsis (2006), studies that examine learning curves long after production has started are not biased if they use a log-linear model. However, they estimate rates of learning for a latter part of the learning curve. Our analysis (subsection 4.3) also uses a log-linear model for experience.
} 
bypass procedure. For example, a quadruple minimally invasive bypass is different from a single bypass procedure, as it involves a greater level of task complexity, duration, and risk. Similarly, performing a valve repair in addition to the bypass procedure can offer more opportunities for the surgeon to learn. The variations of focal procedures are: non-valve single-vessel, non-valve double-vessel, non-valve triple-vessel, non-valve four or more vessel, and valve repair or replacement with any number of bypasses. For a small percentage of non-valve vessel procedures, the number of bypasses was not specified, and we defined this sub-class of procedures as a sixth category. This variety in minimally invasive procedures allows us to define sub-task variety as discussed in 4.3.3 below.

Second, we define a surgeon's related experience as the cumulative volume of all other cardiac procedures, including an on-pump (or regular) CABG surgery, or a surgery on a valve or a structure of the heart. A surgeon's cumulative volume of the non-minimally invasive cardiac procedures therefore constitutes "related" experience, which could also enhance performance for the completion of the focal, i.e. minimally invasive procedures. The following four major categories of related procedures, based on whether the surgery involved a vessel, valve or the septum of the heart are: CABG-only, valve-only, CABG and valve combined, and procedure on the septum.

Finally, we observe the organization (i.e., hospital) in which the surgeon performed the surgeries. This not only allows us to account for the organization-specific drivers of surgeon performance (by using a hospital fixed effect), but also it allows us to account for a given surgeon's firm-specific and non-firm-specific cumulative volume. Table II displays a summary of the case volumes and outcomes for surgeons in our sample. We find a wide variety of cumulative case volumes as well as task variety across related and focal tasks, as demonstrated by the high standard deviations. For some surgeons, minimally invasive procedures comprise a large percentage of their total volume of surgeries performed, whereas other surgeons perform a relatively small number of these procedures.

\subsection{Empirical Strategy}

We now develop the empirical specifications for testing the hypotheses outlined in Section 3. In the discussions below, the subscript $s$ denotes the surgeon, $i$ denotes the patient, $h$ denotes the hospital, and $t$ denotes time. As described earlier, the surgical outcome variable that we study is 
incidence of the 30-day post-operative mortality. Specifically, $M O R T_{i s h t}=1$ if patient $i$, who underwent a cardiac procedure performed by surgeon $s$ in hospital $h$ at time $t$, died, and 0 otherwise. We include a number of known risk factors in a multivariate regression to produce a risk-adjusted mortality rate. Multivariate logistic regression is widely used to model such binary outcomes in cardiac surgery (Nashef et al. 2002; KC, Terwiesch and Horak 2009), and in the operations literature on productivity and quality of care (Huckman and Pisano 2006; KC and Terwiesch 2009). We use the vector $X_{i t}$ to denote patient-level covariates that are known to impact outcomes. In particular, $\mathrm{X}_{\mathrm{it}}$ includes patient demographic factors as well as clinical risk factors (as outlined in Table A-1).

Our primary explanatory variable is the cumulative volume of procedures performed by surgeon $s$ at time $t$. Specifically, we define the cumulative experience as follows:

$$
E_{s t}=\sum_{t^{\prime}=t_{0}}^{t} \sum_{i} I_{i s t^{\prime}}
$$

where $I_{i s t^{\prime}}=1$ if surgeon $s$ performed a minimally invasive cardiac procedure on patient $i$ at time $t$ between the beginning of our study period $\left(t_{0}\right)$ and time $t$, and 0 otherwise. To investigate learning at the individual surgeon level, we start with the following empirical specification:

$$
\ln \left[\frac{\operatorname{Pr}\left(M O R T_{i s h t}=1 \mid X_{i t}\right)}{1-\operatorname{Pr}\left(M O R T_{i s h t}=1 \mid X_{i t}\right)}\right]=\alpha+X_{i t} \beta+S_{s}+H_{h}+T_{t}+\gamma E_{s t}+\varepsilon_{i s h t}
$$

$S_{s}$ denotes the "surgeon fixed effect." This allows us to account for unobserved surgeon-level heterogeneity, including reputation, training and medical background. $H_{h}$ is the hospital fixed effect, which allows us to account for unobserved hospital-level heterogeneity. The vector $T_{t}$ includes temporal factors, including time period when the surgery was performed (specifically, a unique identifier for month and year of a procedure) as well as its day of the week. The time fixed effect allows us to account for any changes in the underlying technology over time. Our estimator of concern is $\gamma$, which captures the effect of an additional unit of experience (i.e., one more single cardiac procedure) for surgeon $s$ in reducing the likelihood of risk-adjusted mortality for patient $i$ at time $t$. $\varepsilon_{\text {isht }}$ is the random error term. The above specification follows a long line of research in cardiac risk stratification that link patient risk variables to outcomes using a logistic regression (see also, Parsonnet, Dean and Bernstein 1989; Higgins et al. 1992; Nashef et al. 2002). We augment this prior work to examine the effect of cumulative experience. Based on 
existing theory from the learning literature, we expect $\gamma<0$.

\subsubsection{Effect of Focal and Related Experiences}

To explore the effects of focal and related experiences on individual learning, we define the variables $E \_F O C_{s t}$ and $E \_R E L_{s t}$ respectively as follows:

$$
E_{-} F O C_{s t}=\sum_{t^{\prime}=t_{0}}^{t} \sum_{i} J_{i s t^{\prime}}
$$

and

$$
E_{-} R E L_{s t}=\sum_{t^{\prime}=t_{0}}^{t} \sum_{i} K_{i s t^{\prime}}
$$

In the first specification, $J_{i s t^{\prime}}=1$ if surgeon $s$ performed a minimally invasive CABG (our focal task) on patient $i$ at time $t^{\prime}$, and 0 otherwise. In the second specification, $K_{i s t^{\prime}}=1$ if surgeon $s$ performed any related cardiac procedure on patient $i$ at time $t$, and 0 otherwise. E_FOC $C_{s t}$ and $E_{-} R E L_{s t}$ therefore capture the cumulative experience in focal and related tasks by surgeon $s$ by time $t$ respectively.

We estimate the effect of focal and related experience on learning using the following logistic specification:

$$
\begin{aligned}
& \ln \left[\frac{\operatorname{Pr}\left(M O R T_{i s h t}=1 \mid X_{i t}\right)}{1-\operatorname{Pr}\left(M O R T_{\text {isht }}=1 \mid X_{i t}\right)}\right] \\
& \quad=\alpha+\boldsymbol{X}_{i t} \alpha_{0}+S_{s}+H_{h}+T_{t}+\alpha_{1} E_{-} F O C_{s t}+\alpha_{2} E_{-} R E L_{s t}+\varepsilon_{\text {isht }}
\end{aligned}
$$

$\alpha_{1}$ and $\alpha_{2}$ capture the effect of focal and related learning on improving outcomes and Hypothesis 1 predicts that $\alpha_{1}<\alpha_{2}$

\subsubsection{Effect of Sub-task Variety on Learning}

The class of minimally invasive cardiac bypass surgeries can be further categorized into six distinct sub-types of procedures, depending on the number of vessels bypassed, and on the incidence of a valve repair or replacement. In our analysis, we draw on prior literature (Narayanan et al. 2009) and quantify the task variety using the Herfindahl-Hirschman Index (HHI), which is defined as follows: 


$$
H H I_{-} F O C_{s t}=\sum_{f}\left(\frac{E_{-} F O C_{s t f}}{E_{-} F O C_{s t}}\right)^{2}
$$

where $E \_F O C_{s t f}$ is the cumulative experience of surgeon $s$ in performing the minimally invasive surgery of sub-type $f$ by time $t$.

Similarly, we identify four distinct types of related cardiac procedures depending on whether the procedure was performed on a vessel, valve or heart septum. We define the variety in related procedures as follows:

$$
H H I_{-} R E L_{s t}=\sum_{r}\left(\frac{E_{-} R E L_{s t r}}{E_{-} R E L_{s t}}\right)^{2}
$$

where $E \_R E L_{s t r}$ is the cumulative experience of surgeon $s$ in performing the related surgery of sub-type $r$ by time $t$.

To explore the impact of sub-task variety in focal and related tasks on learning, we employ the following empirical specification:

$$
\begin{aligned}
\ln \left[\frac{\operatorname{Pr}\left(M O R T_{i s h t}=1 \mid X_{i t}\right)}{1-\operatorname{Pr}\left(M O R T_{i s h t}=1 \mid X_{i t}\right)}\right] \\
=\alpha+X_{i t} \beta_{0}+S_{s}+H_{h}+T_{t}+\beta_{1} E_{-} F O C_{s t}+\beta_{2} E_{-} R E L_{s t}+\beta_{3} H H I_{-} F O C_{s t} \\
+\beta_{4} H H I_{-} F O C_{s t}^{2}+\beta_{5} H H I_{-} R E L_{s t}+\beta_{6} H H I_{-} R E L_{s t}^{2}+\varepsilon_{i s h t}
\end{aligned}
$$

We note that values close to 1 for the Herfindahl-Hirschman Index denote a lack of subtask variety, whereas values closer to 0 denotes the highest levels of sub-task variety. From our hypothesis development, we expect $\beta_{3}$ to be negative, $\beta_{4}$ to be positive, $\beta_{5}$ to be positive and for $\beta_{6}$ to be negative.

\subsubsection{Firm-Specificity of Focal and Related Experiences}

To explore the effects of firm-specificity of focal and related experiences on individual learning, we define the variables $E \_F S \_F O C_{\text {sht }}$ and $E \_N O N \_F S \_F O C_{\text {sht }}$ respectively as follows:

$$
E_{-} F S_{-} F O C_{s h t}=\sum_{t^{\prime}=t_{0}}^{t} \sum_{i} F S_{-} L_{i s h t^{\prime}}
$$

and

$$
E_{-} N O N \_F S \_F O C_{s h t}=\sum_{t^{\prime}=t_{0}}^{t} \sum_{i} N O N_{-} F S_{-} L_{i s h t^{\prime}}
$$


In the first specification, $F S_{-} L_{i s h t^{\prime}}=1$ if surgeon $s$ performed any minimally invasive CABG on patient $i$ at time $t^{\prime}$ in hospital $h$, and 0 otherwise. In the second specification, NON_FS_L $L_{i s h t^{\prime}}=1$ if surgeon $s$ performed any minimally invasive CABG on patient $i$ at time $t$ in any hospital other than hospital $h . E \_F S \_F O C_{\text {sht }}$ and $E \_N O N \_F S \_F O C_{\text {sht }}$ therefore capture the firm-specific and the non-firm-specific cumulative experience in focal tasks by surgeon $s$ by time $t$ respectively. The firm-specific $\left(E \_F S \_R E L_{s h t}\right)$ and non-firm-specific $\left(E \_N O N \_F S \_R E L_{s h t}\right)$ cumulative experience in related tasks by surgeon $s$ by time $t$ are constructed similarly.

We estimate the effect of firm-specific focal and related experience on learning using the following logistic specification:

$$
\begin{aligned}
\ln \left[\frac{\operatorname{Pr}\left(M O R T_{i s h t}=1 \mid X_{i t}\right)}{1-\operatorname{Pr}\left(M O R T_{i s h t}=1 \mid X_{i t}\right)}\right] \\
=\alpha+\boldsymbol{X}_{i t} \gamma_{0}+S_{s}+H_{h}+T_{t}+\gamma_{1} E_{-} F S_{-} F O C_{s h t}+\gamma_{2} E_{-} N O N_{-} F S_{-} F O C_{s h t} \\
+\gamma_{3} E_{-} F S_{-} R E L_{s h t}+\gamma_{4} E_{-} N O N_{-} F S_{-} R E L_{s h t}+\gamma_{5} H H I_{-} F O C_{s t} \\
+\gamma_{6} H H I_{-} F O C_{s t}^{2}+\gamma_{7} H H I_{-} R E L_{s t}+\gamma_{8} H H I_{-} R E L_{s t}^{2}+\varepsilon_{i s h t}
\end{aligned}
$$

$\gamma_{1}$ and $\gamma_{2}$ capture the effect of firm-specific and non-firm-specific focal learning on improving outcomes, and $\gamma_{3}$ and $\gamma_{4}$ capture the effect of firm-specific and non-firm-specific related learning on improving outcomes respectively. Finally, to test Hypotheses 5 and 6 we interact the firm-specific and non-firm specific variables for focal and related experience.

$$
\begin{aligned}
& \ln \left[\frac{\operatorname{Pr}\left(M O R T_{i s h t}=1 \mid X_{i t}\right)}{1-\operatorname{Pr}\left(M O R T_{i s h t}=1 \mid X_{i t}\right)}\right] \\
&=\alpha+X_{i t} \gamma_{0}+S_{S}+H_{h}+T_{t}+\gamma_{1} E_{-} F S_{-} F O C_{s h t}+\gamma_{2} E_{-} N O N_{-} F S_{-} F O C_{s h t} \\
&+\gamma_{3} E_{-} N O N_{-} F S_{-} F O C_{s h t}+\gamma_{4} E_{-} F S_{-} F O C_{s h t} X E_{-} N O N_{-} F S_{-} F O C_{s h t} \\
&+\gamma_{5} E_{-} F S_{-} R E L_{s h t}+\gamma_{6} E_{-} N O N_{-} F S_{-} R E L_{s h t} \\
&+\gamma_{7} E_{-} F S_{-} R E L_{s h t} X E_{-} N O N_{-} F S_{-} R E L_{s h t}+\gamma_{8} H H I_{-} F O C_{s t} \\
&+\gamma_{9} H H I_{-} F O C_{s t}^{2}+\gamma_{10} H H I_{-} R E L_{s t}+\gamma_{11} H H I_{-} R E L_{s t}^{2}+\varepsilon_{i s h t}
\end{aligned}
$$

\section{Results}

We find (Table IV) that focal experience is related to an improvement in surgical outcome, as measured by the decreased likelihood of mortality for a patient, demonstrated by the negative and statistically significant coefficient of cumulative volume of minimally invasive surgical 
procedures (column 1, coefficient $=-0.00398)$. This corresponds to a reduction in odds of mortality by $0.39 \%$ due to the experience of performing one additional procedure; the corresponding reduction in odds of mortality from increasing cumulative procedural volume by one standard deviation (87 procedures) is $29.2 \%$. We also find that related experience is associated with improved surgical outcomes, as demonstrated by the negative and statistically significant effect for individual surgeon related experience (column 1, coefficient $=-0.00094$ ). Although both coefficients are related to improved surgical performance, the coefficient on focal experience is significantly larger in magnitude than the coefficient on related experience ( $\mathrm{p}<0.01$ ), supporting Hypothesis 1. The month and year fixed effects capture the effect of temporal improvements (e.g. through better technology) during the period of study. Therefore, our individual surgeon estimates are obtained from cumulative experience above and beyond these temporal factors. The patient-level controls, where statistically significant, all have the expected signs. Removing these medical controls or the surgeon fixed effect does not significantly impact the direction and magnitude of our result (column 2); our finding that cumulative volume in both related and focal experiences improve patient outcome is robust to these alternative specifications.

In column 3, Table IV we include the sub-task variety variables for both focal and related experience. As predicted by Hypothesis 2 we find that focal sub-task variety shows an inverted U-shaped relationship with surgical outcomes. That is, surgeons can improve their outcomes with some variety in focal experiences, but excessive focal sub-task variety is detrimental to outcomes. On the other hand, we find that related sub-task variety has a U-shaped relationship with surgical outcomes. In other words, performance is maximized at either maximum or minimum related sub-task variety, providing support for Hypothesis 3 .

Finally, we consider the firm-specificity of focal and related experiences (Table V). We find (column 1) that firm-specific focal experience is related to improved performance, as indicated by the negative coefficient (estimate $=-0.00456, p<0.01$ ). On the other hand, nonfirm-specific focal experience is not significantly related to improved outcomes. Both firmspecific and non-firm-specific related experiences are associated with improved outcomes. However, firm-specificity of related experiences is small, as evidenced by the small difference between the coefficients for firm-specific and non-firm-specific related experiences (difference $=$ $0.00022, p<0.01)$. In contrast, the difference between the coefficients for firm-specific and non- 
firm-specific focal experiences is significantly larger (difference $=0.00882, p<0.01$ ). This provides support for Hypothesis 4. In column 4, we consider the model with interaction effects between firm-specific and non-firm-specific related and focal experiences. We find that the coefficients on both interaction terms are positive (corresponding to an increase in mortality rate). In other words, the returns to firm-specific, focal experience are decreasing in non-firmspecific focal experience. Similarly, the rate of learning from firm-specific, related experience decreases with increases in non-firm-specific related experience. This provides support for Hypothesis 5 and Hypothesis 6, respectively.

\section{Discussion}

In this paper, we examine the complex ways that focal experience and related experience can affect individual performance. Given the findings in this paper, how should surgeons accumulate experience to improve quality outcomes? If access to volume at a given location is not an issue then the recommendations are clear-cut. Surgeon performance is higher when surgeons focus on one procedure type, at one hospital, with a moderate amount of focal sub-task variety. However, actual implementation depends on whether scheduling and case selection are done at the level of the hospital, department, or individual physician. For example, there may not be enough volume in the focal task to justify completely focusing surgeons on procedure types. In that case, surgeons, administrators, and patients should be aware of our findings. While increasing case volume is related to improved performance, not all experience has an equal effect on performance, and some experience may even prove detrimental (Lapré and Nembhard 2010; Ramdas et al. 2010; Argote and Miron-Spektor 2011; Lapré 2011). Therefore, it is necessary to understand the composition of an individual's experience along the dimensions we examine.

First, we find that focal experience has a greater positive effect on performance than related experience. Individual focal experience likely provides more directly relevant knowledge that can be used to aid performance, than does related experience. This result highlights a number of areas for future research. For example, what particular aspects of focal experience are most valuable for performance? Ramdas et al. (2010) find that experience with the individual component of an artificial hip is a significant predictor of task completion time, in some cases. Investigating specific component variants, in addition to tasks, is an important opportunity for future work. A similar question is what knowledge from related experience actually aids 
performance? A related task, e.g., CABG in our setting, involves both some aspects that are similar to the focal task (e.g., grafting the donor vein onto the heart) and some that are not (e.g., using the heart-lung machine). Future work should explore whether learning from related tasks comes from the aspects of related experience that are similar or dissimilar to the focal task. A combination of laboratory experiments and qualitative work would help to further unpack these findings. A second question is on the degree of relatedness needed to provide learning. In the case of cardiac surgery, a surgeon is working on the same organ (the heart) and also bypassing a blocked artery in both cases, so it seems clear the tasks are related. How do differences in factors such as knowledge domain (e.g., doing the same type of procedure on different body parts) affect relatedness and the identified gains?

Further, we find that focal sub-task variety has an inverse-U shaped relationship with patient mortality while related sub-task variety has a $U$ shaped relationship with performance. In other words, some, but not too much sub-task variety aids performance for focal experience, but for related experience either zero or a significant amount of sub-task variety is related to better performance. Focal sub-task variety may be particularly valuable as it helps a surgeon to explore the search space of possible activities within a constrained task. Thus, the surgeon may gain additional knowledge about the task by learning about the processes' underlying causal linkages (Bohn 2005; Bohn and Lapré 2011). However, by engaging in too much variety, performance is hampered. Future work should explore what factors lead to this decrease in performance and consider ways that they may be mitigated.

By splitting sub-task variety into separate focal and related components, we are able to demonstrate their opposite effects on performance. Increased related sub-task variety may be distracting, until eventually with sufficient experience an individual learns to deal with the challenge. The concept of a task shell may be one way that an individual can deal with the cognitive processing challenges of related sub-task variety (Navon and Gopher 1979; Gopher et al. 2000). Future work should explore the mechanism of task shells in more detail and also investigate how the building of task shells both occurs and how it can be expedited.

Additionally, we find that focal experience exhibits greater firm-specificity than does related experience. In examining the result in more detail we find that non-firm focal experience is related to greater patient mortality. This suggests that not only is firm-specific focal experience more valuable for performance, but that non-firm focal experience may be harmful. This is 
consistent with Boris Groysberg's work examining star performers' mobility where he finds that a star's performance actually worsens when the individual switches firms (Groysberg, Lee and Nanda 2008; Groysberg 2010). Experience from another hospital may be misapplied, resulting in higher patient mortality.

Further we find that both types of experience gained at other hospitals hamper learning at the current hospital. In other words, for any given level of firm-specific experience, the more procedures a surgeon has done elsewhere, the slower the firm-specific learning. Given the increasingly large role of free-lancers in the $21^{\text {st }}$ Century economy (Huckman and Pisano 2006), these findings sound a cautionary note. They also highlight the need to understand what organizational-specific resources lead to higher-levels of firm-specificity and what processes could be used to substitute for these effects. Additionally, creating processes to ease the transition and "unlearning" process for freelancers may be an area of fruitful exploration.

We undertook this study to identify factors that might help to improve healthcare outcomes. As such, our work clearly holds policy implications for healthcare professionals. Prior work documents substantial variety in outcomes within healthcare (Dartmouth 2005). One response to this variation has been to call for concentrating procedure types in particular facilities - the regionalization of care (Birkmeyer and Dimick 2009). Our findings on firm-specificity support this idea since increased regionalization of care could lead to less switching between hospitals and therefore higher levels of firm-specific experience. Our results also offer guidance on how tasks might be allocated within a facility both in terms of focal vs. related experience and sub-task variety in both categories. Finally, the findings in this paper suggest that patients might benefit (when they have a choice) from gathering more detailed information about a surgeon's prior experience in order to evaluate the quality performance of different providers.

Although our findings are robust to various empirical specifications, several limitations of our study bear mentioning. First, we have examined factors to improve individual performance within cardiac surgery. While this field is a significant source of costs within the medical system, it is still only one area, and future work should seek to examine our findings in other areas. Second, in this study we examine one performance measure: quality of the surgery. While this measure is commonly used by researchers (e.g., Huckman and Pisano 2006), performance is a multidimensional construct, so future work should examine additional measures of performance, such as procedure completion time and length of stay in the hospital. Third, physician 
characteristics such as medical training and education, age, gender, and history with the hospital organization could also play an important role in individual learning. Although our data set includes the unique physician identifiers that allow us to control for individual physician effects, we did not observe these physician characteristics for the current study. Exploring these drivers of learning could be an area for future research. Fourth, our surgical outcomes are adjusted for patient risk (Novick and Stitt 1999; Treasure and Gallivan 1999) (Novick and Stitt 1999; Treasure and Gallivan 2007) as well as possible temporal changes in the underlying technology. However, risk adjustment is not perfect, and various other clinical factors may be included to provide more comprehensive risk stratification. Finally, a surgeon does not complete an entire surgical procedure by herself. That does not mean that a team of individuals are completing the key surgical processes on the heart, that is the job of the cardiothoracic surgeon, but other members in the operating room such as nurses or the anesthesiologist can play an important role. While repeated experience between team members may aid performance (Edmondson et al. 2003; Huckman et al. 2009; Huckman and Staats 2011), similar to other healthcare studies we do not have data about anyone on the team besides the surgeon (e.g., Novick and Stitt 1999; Reagans, Argote and Brooks 2005; Huckman and Pisano 2006). Future work should seek to collect data on all team members involved in the surgical procedure and explore how their familiarity may affect the results reported here.

\section{Conclusion}

Scholars have noted that improving knowledge workers' performance may be the most significant management challenge for the twenty-first century (Drucker 1999). Perhaps nowhere is this challenge more pressing than in healthcare, where the need for improvement is often literally a matter of life or death. Dr. Cam Patterson, chief of cardiology at UNC Hospitals and associate dean for health-care entrepreneurship notes, "As the practice of medicine relies increasingly on technological innovation, it is critically important that we master and teach the most challenging medical and surgical procedures in the shortest time possible (Lester 2011)." This paper helps to answer this question by examining how focal and related experience may differentially affect individual performance.

In so doing, this study makes several contributions to the healthcare, learning, and operations management literatures. The first comes from introducing quality as a dependent 
variable to the study of focal and related experience. Prior work has not examined these factors' relationship to quality, a vital performance measure not only in healthcare, but in many settings.

Second, we study specialization and variety in task experience in a procedure near its introduction to the field. Thus, we are able to study most individuals' entire learning curve and, in so doing, gain insight into factors that improve learning for novel process improvements those processes that not only will be vital for enhancing the quality of care within health services, but also will serve as a basis for operational improvement.

Third, recent work on specialization and variety calls for more nuanced investigations of the relatedness of work (Staats and Gino 2011). We respond to this call by investigating variety within the traditional categories of focal experience and related experience, and find that sub-task variety exhibits opposite $\mathrm{U}$ shaped performance relationships for focal and related experience. By examining specialization and variety in more detail we gain insight into the relationships and potential mechanisms that affect each strategy.

Fourth, we not only examine the firm-specificity of focal and related experience, but also we introduce and study the interaction between firm-specific and non-firm-specific experience. Individuals are embedded in complex social systems, and with our work we start to understand how surgeons can benefit from or be harmed by the contextual experience that they gain.

Finally, by studying factors that can improve learning within operational systems, our work responds to calls to build more behavioral theory in operations (Boudreau et al. 2003; Bendoly, Donohue and Schultz 2006; Gino and Pisano 2008). Altogether, by studying factors that improve individual learning and performance, this work informs not only the practice of healthcare, but operations more generally, as organizations seek to deliver higher-quality output. 


\section{Tables and Figures}

Table I

Patient Summary Statistics

\begin{tabular}{lccc}
\hline \hline Variable & Mean & Standard Deviation & Median \\
\hline Risk Adjusted Mortality & 0.0353 & 0.06625 & 0.0122 \\
Age & 67.53 & 11.16 & 69 \\
Gender (Female = 1) & 0.287 & 0.453 & 0 \\
Charlson Score & 0.909 & 1.034 & 1 \\
Cerebrovascular Disease & 0.0904 & 0.287 & 0 \\
COPD & 0.157 & 0.364 & 0 \\
Diabetes & 0.290 & 0.454 & 0 \\
Diabetes with Complications & 0.0517 & 0.221 & 0 \\
Chronic Renal Failure & 0.050 & 0.218 & 0 \\
Incidence of Myocardial Infarction & 0.292 & 0.454 & 0 \\
PTCA & 0.0395 & 0.195 & 0 \\
\hline \hline
\end{tabular}

$\mathrm{N}=6516$ Patients

Table II

Surgeon Summary Statistics

\begin{tabular}{lccc}
\hline \hline Variable & Mean & Standard Deviation & Median \\
\hline Focal Experience & 91.05 & 86.75 & 64 \\
Related Experience & 321.29 & 340.74 & 192 \\
Firm-Specific Focal Exp. & 81.99 & 81.56 & 56.0 \\
Firm-Specific Related Exp. & 290.3 & 326.1 & 167 \\
Non-Firm Focal Exp. & 9.07 & 34.6 & 0.0 \\
Non-Firm Related Exp. & 31.0 & 115.244 & 0.0 \\
Focal Experience HHI & 0.282 & 0.116 & 0.260 \\
Related Experience HHI & 0.543 & 0.118 & 0.554 \\
\hline \hline
\end{tabular}

$\mathrm{N}=71$ Surgeons

Table III

Correlation Matrix

\begin{tabular}{lrrrrrrrr}
\hline \hline Variable & 1 & 2 & 3 & 4 & 5 & 6 & 7 & 8 \\
\hline 1. Risk-Adjusted Mortality & 1 & & & & & & & \\
2. Focal Experience & -0.1 & 1 & & & & & & \\
3. Related Experience & 0.0769 & 0.218 & 1 & & & & & \\
4. Firm-Specific Focal Exp. & -0.0811 & 0.917 & 0.171 & 1 & & & & \\
5. Non-Firm Focal Exp. & -0.0614 & 0.345 & 0.143 & -0.0573 & 1 & & & \\
6. Firm-Specific Related Exp. & 0.089 & 0.192 & 0.941 & -0.04116 & -0.0411 & 1 & & \\
7. Non-Firm Related Exp. & -0.0245 & 0.103 & 0.294 & -0.119 & 0.5399 & -0.0466 & & 1 \\
8. HHI Focal & -0.0114 & -0.242 & -0.249 & -0.239 & -0.043 & -0.234 & -0.0752 & 1 \\
9. HHI Related & -0.116 & -0.0358 & -0.404 & -0.0693 & 0.0736 & -0.435 & 0.0351 & 0.185 \\
\hline \hline
\end{tabular}


Table IV

Effect of Focal and Related Experience on Post-Operative Mortality Rate

\begin{tabular}{|c|c|c|c|}
\hline & $\begin{array}{l}\text { Focal and Related Exp. } \\
\text { (1) }\end{array}$ & $\begin{array}{l}\text { Without Patient Controls } \\
\text { (2) }\end{array}$ & $\begin{array}{c}\text { Focal and Related Sub-task } \\
\text { Variety } \\
\text { (3) }\end{array}$ \\
\hline Surgeon Fixed Effect & Yes & Yes & Yes \\
\hline Hospital Fixed Effect & Yes & Yes & Yes \\
\hline Month and Year Fixed Effect & Yes & Yes & Yes \\
\hline Day of Week & Yes & Yes & Yes \\
\hline Patient Controls & Yes & No & Yes \\
\hline Focal Experience & $-0.00398(0.0000) * * *$ & $-0.00394(0.000) * * *$ & $-0.00387(0.000) * * *$ \\
\hline Related Experience & $-0.00094\left(3.56 \times 10^{-6}\right) * * *$ & $-0.00020\left(3.50 \times 10^{-6}\right) * *$ & $-0.00053\left(3.6 \times 10^{-6}\right) * * *$ \\
\hline Focal HHI & - & - & $-0.424(0.005) * * *$ \\
\hline Focal HHI Sq. & - & - & $1.093(0.0098) * * *$ \\
\hline Related HHI & - & - & $1.195(0.003) * * *$ \\
\hline Related HHI Sq. & - & - & $-1.697(0.0055) * * *$ \\
\hline Likelihood Ratio (Pro > ChiSq) & $<0.0001$ & $<0.0001$ & $<0.0001$ \\
\hline Max-rescaled R-Square & 0.273 & 0.273 & 0.2897 \\
\hline Area under ROC & 0.878 & 0.878 & 0.877 \\
\hline
\end{tabular}

$$
N=6516 \text { Asymptotic Standard Errors in Parentheses. }{ }^{\wedge}=p<.10, *=p<0.05, * *=p<.01, * * *=p<.001 .
$$

Table V

Effect of Firm Specific and Non-Firm Specific Focal and Related Experience on Post- Operative Mortality Rate

\begin{tabular}{|c|c|c|c|}
\hline & $\begin{array}{l}\text { Firm and Other } \\
\text { (1) }\end{array}$ & $\begin{array}{c}\text { Without Sub-task } \\
\text { Variety } \\
(2)\end{array}$ & $\begin{array}{l}\text { Full Model } \\
\text { (3) }\end{array}$ \\
\hline Surgeon Fixed Effect & Yes & Yes & Yes \\
\hline Hospital Fixed Effect & Yes & Yes & Yes \\
\hline Month and Year Fixed Effect & Yes & Yes & Yes \\
\hline Day of Week & Yes & Yes & Yes \\
\hline Patient Controls & Yes & Yes & Yes \\
\hline \multirow[t]{2}{*}{ Firm Specific Focal } & -0.00456 & -0.00553 & -0.00609 \\
\hline & $(0.0000) * * *$ & $(0.0000) * * *$ & $(0.0000) * * *$ \\
\hline \multirow[t]{2}{*}{ Non-Firm Focal } & 0.00426 & 0.00336 & 0.0022 \\
\hline & $(0.0001) * * *$ & $(0.0000) * * *$ & $(0.0000) * * *$ \\
\hline \multirow[t]{2}{*}{ Firm Specific Related } & -0.00058 & -0.00066 & -0.00066 \\
\hline & $\left(3.78 \times 10^{-6}\right) * * *$ & $\left(3.79 \times 10^{-6}\right) * * *$ & $\left(3.76 \times 10^{-6}\right) * * *$ \\
\hline \multirow[t]{2}{*}{ Non-Firm Related } & -0.00036 & -0.00086 & -0.00071 \\
\hline & $(0.000017) * * *$ & $(0.000017) * * *$ & $(0.000017) * * *$ \\
\hline \multirow[t]{2}{*}{ Firm-Specific x Non-Firm Focal } & - & 0.000091 & 0.000106 \\
\hline & & $\left(1.42 \times 10^{-6}\right) * * *$ & $\left(1.41 \times 10^{-6}\right) * * *$ \\
\hline Firm-Specific x Non-Firm Related & - & $\begin{array}{c}1.04 \times 10^{-6} \\
\left(3.27 \times 10^{-8}\right) * * *\end{array}$ & $\begin{array}{c}8.66 \times 10^{-6} \\
\left(3.28 \times 10^{-8}\right) * * *\end{array}$ \\
\hline Focal HHI & $-0.327(0.005) * * *$ & - & $-0.0987(0.0056) * * *$ \\
\hline Focal HHI Sq. & $0.998(0.0098) * * *$ & - & $0.961(0.0098) * * *$ \\
\hline Related HHI & $0.78(0.003) * * *$ & - & $0.391(0.003) * * *$ \\
\hline Related HHI Sq. & $-1.583(0.00518) * * *$ & - & $-1.411(0.005) * * *$ \\
\hline Likelihood Ratio (Pro > ChiSq) & $<0.0001$ & $<0.0001$ & $<0.0001$ \\
\hline Max-rescaled R-Square & 0.283 & 0.293 & 0.248 \\
\hline Area under ROC & 0.877 & 0.874 & 0.878 \\
\hline
\end{tabular}




\section{References}

Abernathy, W. J. and J. M. Utterback (1978). "Patterns of industrial innovation." Technol. Rev. 80(7): 4047.

Adler, P. S., M. Benner, D. J. Brunner, J. P. MacDuffie, E. Osono, B. R. Staats, H. Takeuchi, M. Tushman and S. G. Winter (2009). "Perspectives on the productivity dilemma." J. of Operations Management 27(2): 99-113.

AHA (2008). American Hospital Association Annual Survey of Hospitals, American Hospital Association.

Allport, A. and G. Wylie (1999). Task-switching: Positive and negative priming of task-set. Attention, Space and Action: Studies in Cognitive Neuroscience. G. W. Humphreys, J. Duncan and A. M. Treisman. Oxford, Oxford University Press: 273-296.

Allport, D. A., E. A. Styles and S. Hsieh (1994). Shifting intentional set: Exploring the dynamic control of tasks. Attention and Performance XV. C. Umilta and M. Moscovitch. Cambridge, MA, MIT Press: 421-452.

Anagnostopoulos, C., S. Siminelakis, O. Ananiadou, A. Katsaraki, G. Drossos, D. Katritsis, J. Panagiotopoulos and G. Papadopoulos (2003). "Learning curves of cardiac surgery in relation to risk stratification and hospital location." Journal of Cardiovascular Surgery 44(5): 591-596.

Anderson, J. R. (1982). "Acquisition of cognitive skill." Psych. Rev. 89(4): 369-406.

Argote, L. and E. Miron-Spektor (2011). "Organizational learning: From experience to knowledge." Organ. Sci. 22(5): 1123-1137.

Bendoly, E., K. Donohue and K. L. Schultz (2006). "Behavior in operations management: Assessing recent findings and revisiting old assumptions." J. of Operations Management 24(6): 737-752.

Birkmeyer, J. D. and J. B. Dimick (2009). "Understanding and reducing variation in surgical mortality." Annual Review of Medicine 60(1): 405-415.

Birkmeyer, J. D., T. A. Stukel, A. E. Siewers, P. P. Goodney, D. E. Wennberg and F. L. Lucas (2003). "Surgeon volume and operative mortality in the United States." N. Engl. J. Med. 349(22): 21172127.

Boh, W. F., S. A. Slaughter and J. A. Espinosa (2007). "Learning from experience in software development: A multilevel analysis." Management Sci. 53(8): 1315-1331.

Bohn, R. E. (2005). "From art to science in manufacturing: The evolution of technological knowledge." Foundations and Trends in Technology, Information and Operations Management 1(2): 129-212.

Bohn, R. E. and M. A. Lapré (2011). Accelerated learning by experimentation. Learning Curves: Theory, Models, and Applications. M. Y. Jaber. Boca Raton, FL, CRC Press, Taylor and Francis.

Boudreau, J., W. Hopp, J. O. McClain and L. J. Thomas (2003). "On the interface between operations and human resources management." Manufacturing Service Oper. Management 5(3): 179-202.

Chase, W. G. and H. A. Simon (1973). "Perception in chess." Cognitive Psych. 4(1): 55-81.

Clark, J. R. and R. S. Huckman (Forthcoming). "Broadening focus: Spillovers and the benefits of specialization in the hospital industry." Management Sci.

Clark, K. B. (1985). "The interaction of design hierarchies and market concepts in technological evolution." Research Policy 14(5): 235-251.

Dartmouth. (2005). "Dartmouth Atlas of Health Care: Studies of surgical variation." Retrieved March 18,2011 , from http://www.dartmouthatlas.org/downloads/reports/Cardiac_report_2005.pdf.

De Leval, M. R. (1997). "Human factors and surgical outcomes: A Cartesian dream." Lancet 349(9053): 723-725.

Drucker, P. F. (1999). Management Challenges for the 21st Century. New York, HarperBusiness.

Edmondson, A. C. (2002). "The local and variegated nature of learning in organizations: A group-level perspective." Organ. Sci. 13(2): 128. 
Edmondson, A. C., R. M. Bohmer and G. P. Pisano (2001). "Disrupted routines: Team learning and new technology implementation in hospitals." Administrative Sci. Q. 46(4): 685-716.

Edmondson, A. C., A. Winslow, R. Bohmer and G. P. Pisano (2003). "Learning how and learning what: Effects of tacit and codified knowledge on performance improvement following technology adoption." Decision Sci. 34(2): 197-223.

Ellis, H. C. (1965). The transfer of learning. New York, Macmillan.

Fleming, L. (2001). "Recombinant uncertainty in technological search." Management Sci. 47(1): 117-132.

Friedrich, G. J., J. Bonatti and O. E. Dapunt (1997). "Preliminary experience with minimally invasive coronary-artery bypass surgery combined with coronary angioplasty." N. Engl. J. Med. 336(20): 1454-1455.

Gardner, D. (2001). CardioThoracic Systems. Harvard Business School Case 9-899-281. Boston.

Gick, M. L. and K. J. Holyoak (1980). "Analogical problem solving." Cognitive Psych. 12(3): 306-355.

Gino, F. and G. P. Pisano (2008). "Toward a theory of behavioral operations." Manufacturing Service Oper. Management 10(4): 676-691.

Gopher, D., L. Armony and Y. Greenshpan (2000). "Switching tasks and attention policies." J of Experimental Psych: General 129(3): 308-339.

Groysberg, B. (2010). Chasing Stars: The Myth of Talent and the Portability of Performance, Princeton University Press.

Groysberg, B., L.-E. Lee and A. Nanda (2008). "Can they take it with them? The portability of star knowledge workers' performance: Myth or reality." Management Sci. 54(7): 1213 - 1230.

Hackman, J. R. (1969). "The nature of the task as a determiner of job behavior." Pers. Psych. 22: 435444.

Hackman, J. R. and G. R. Oldham (1976). "Motivation through the design of work: Test of a theory." Organ. Behav. Human Decision Processes 16(2): 250-279.

Hammond, J. W., W. S. Queale, T. Kim and E. G. McFarland (2003). "Surgeon experience and clinical and economic outcomes for shoulder arthroplasty." J Bone Joint Surg Am 85(12): 2318-2324.

Hannan, E. L., H. Kilburn, J. F. O'Donnell, G. Lukacik and E. P. Shields (1990). "Adult open heart surgery in New York state." JAMA 264(21): 2768-2774.

Hargadon, A. and R. I. Sutton (1997). "Technology brokering and innovation in a product development firm." Administrative Sci. Q. 42(4): 716-749.

Herzberg, F. (1966). Work and the Nature of Man. Cleveland, World Pub. Co.

Higgins, T. L., F. G. Estafanous, F. D. Loop, G. J. Beck, J. M. Blum and L. Paranandi (1992). "Stratification of morbidity and mortality outcome by preoperative risk factors in coronary artery bypass patients." JAMA 267(17): 2344-2348.

Huckman, R. S. (2003). "The utilization of competing technologies within the firm: Evidence from cardiac procedures." Management Sci. 49(5): 599-617.

Huckman, R. S. and G. P. Pisano (2006). "The firm specificity of individual performance: Evidence from cardiac surgery." Management Sci. 52(4): 473-488.

Huckman, R. S. and B. R. Staats (2011). "Fluid tasks and fluid teams: The impact of diversity in experience and team familiarity on team performance." Manufacturing Service Oper. Management 13(3): 310-328.

Huckman, R. S., B. R. Staats and D. M. Upton (2009). "Team familiarity, role experience, and performance: Evidence from Indian software services." Management Sci. 55(1): 85-100.

Huckman, R. S. and D. Zinner (2008). "Does focus improve operational performance? Lessons from the management of clinical trials." Strategic Management J. 29(2): 173-193.

Imai, M. (1986). Kaizen: The Key to Japanese Competitive Success. New York, Random House Business.

Johnson, M. K. and L. Hasher (1987). "Human learning and memory." Ann. Rev. Pscyhol. 38: 631-669.

Kaiser. (2011). "Kaiser Family Foundation: U.S. Health Care Costs." Retrieved March 15, 2011, from http://www.kaiseredu.org/Issue-Modules/US-Health-Care-Costs/Background-Brief.aspx. 
KC, D. and C. Terwiesch (2009). "Impact of workload on service time and patient safety: An econometric analysis of hospital operations." Management Sci. 55(9): 1486-1498.

KC, D. and C. Terwiesch (2011). "The effects of focus on performance: Evidence from California hospitals." Management Sci. 57(11): 1897-1912.

KC, D., C. Terwiesch and J. Horak (2009). "Cardiothoracic surgery risk stratification for intra-hospital decision making and inter-hospital quality comparisons." Wharton School Working Paper.

Lapré, M. A. (2011). Inside the learning curve: Opening the black box of the learning curve. Learning Curves: Theory, Models, and Applications. M. Y. Jaber. Boca Raton, FL, CRC Press, Taylor and Francis.

Lapré, M. A. and I. M. Nembhard (2010). "Inside the organizational learning curve: Understanding the organizational learning process." Foundations and Trends in Technology, Information and Operations Management 4(1): 1-103.

Lapré, M. A. and N. Tsikriktsis (2006). "Organizational learning curves for customer dissatisfaction: Heterogeneity across airlines." Management Sci. 52(3): 352-366.

Lester, M. C. (2011). "Toward faster, more effective learning." UNC Business(Fall).

Levinthal, D. and C. Rerup (2006). "Crossing an apparent chasm: Bridging mindful and less-mindful perspectives on organizational learning." Organ. Sci. 17(4): 502-513.

Luft, H. S., D. W. Garnick, D. H. Mark and S. J. McPhee (1990). Hospital Volume, Physician Volume, and Patient Outcomes: Assessing the Evidence. Ann Arbor, MI, Health Administration Press.

MacDuffie, J. P., K. Sethuraman and M. L. Fisher (1996). "Product variety and manufacturing performance: Evidence from the international automotive assembly plant study." Management Sci. 42(3): 350-369.

Mishina, K. (1999). Learning by new experiences: Revisiting the flying fortress learning curve. Learning by Doing in Markets, Firms, and Countries. N. R. Lamoreaux, D. M. G. Raff and P. Temin. Chicago, University of Chicago Press: 145-179.

Monsell, S. (2003). "Task switching." Trends in cognitive sciences 7(3): 134-140.

Narayanan, S., S. Balasubramanian and J. M. Swaminathan (2009). "A matter of balance: Specialization, task variety, and individual learning in a software maintenance environment." Management Sci. 55(11): 1861-1876.

Nashef, S. A., F. Roques, B. G. Hammill, E. D. Peterson, P. Michel, F. L. Grover, R. K. Wyse and T. B. Ferguson (2002). "Validation of European System for Cardiac Operative Risk Evaluation (EuroSCORE) in North American cardiac surgery " Eur. J. Cardiothoracic Surgery 22: 101-105.

Navon, D. and D. Gopher (1979). "On the economy of the human-processing system." Psych. Rev. 86(3): 214-255.

Novick, R. J. and L. W. Stitt (1999). "The learning curve of an academic cardiac surgeon: Use of the CUSUM Method." Journal of Cardiac Surgery 14(5): 312-320.

Parsonnet, V., D. Dean and A. D. Bernstein (1989). "A method of uniform stratification of risk for evaluating the results of surgery in acquired adult heart disease." Circulation 79(6 Pt 2): I3-12.

Pisano, G. P., R. M. J. Bohmer and A. C. Edmondson (2001). "Organizational differences in rates of learning: Evidence from the adoption of minimally invasive cardiac surgery." Management Sci. 47(6): $752-768$.

Puskas, J. D., C. E. Wright, R. S. Ronson, W. M. BrownIII, J. P. Gott and R. A. Guyton (1998). "Offpump multivessel coronary bypass via sternotomy is safe and effective." The Annals of Thoracic Surgery 66(3): 1068-1072.

Ramdas, K., K. Saleh, S. Stern and H. Liu (2010). The impact of surgical device choice on outcomes in hip replacement surgery. Research seminar, Information Systems \& Operations Management Department, Goizueta Business School, Emory University.

Reagans, R., L. Argote and D. Brooks (2005). "Individual experience and experience working together: Predicting learning rates from knowing who knows what and knowing how to work together." Management Sci. 51(6): 869-881. 
Roach, G. W., M. Kanchuger, C. M. Mangano, M. Newman, N. Nussmeier, R. Wolman, A. Aggarwal, K. Marschall, S. H. Graham, C. Ley, G. Ozanne, D. T. Mangano, A. Herskowitz, V. Katseva and R. Sears (1996). "Adverse Cerebral Outcomes after Coronary Bypass Surgery." N. Engl. J. Med. 335(25): 1857-1864.

Rubinstein, J. S., D. E. Meyer and J. E. Evans (2001). "Executive control of cognitive processes in task switching." J of Experimental Psych: Human Perception and Performance 27(4): 763.

Sarason, I. G. and G. R. Pierce (1996). Cognitive Interference, Lawrence Erlbaum Associates.

Schilling, M. A., P. Vidal, R. E. Ployhart and A. Marangoni (2003). "Learning by doing something else: Variation, relatedness, and the learning curve." Management Sci. 49(1): 39-56.

Schultz, K. L., J. O. McClain and L. J. Thomas (2003). "Overcoming the dark side of worker flexibility." J. of Operations Management 21(1): 81-92.

Simon, H. A. (1962). "The architecture of complexity." Proceedings of the American Philosophical Society 106(6): 467-482.

Skinner, W. (1974). "The focused factory." Harvard Business Rev. 52(3): 113.

Skinner, W. (1985). The taming of lions: How manufacturing leadership evolved. The Uneasy Alliance: Managing the Productivity-Technology Dilemma. K. B. Clark, R. H. Hayes and C. Lorenz. Boston, HBS Press.

Sosa, J. A., H. M. Bowman, J. M. Tielsch, N. R. Powe, T. A. Gordon and R. Udelsman (1998). "The importance of surgeon experience for clinical and economic outcomes from thyroidectomy." Annals of Surgery 228(3): 320-330.

Speier, C., J. S. Valacich and I. Vessey (1999). "The influence of task interruption on individual decision making: An information overload perspective." Decision Sci. 30(2): 337-360.

Staats, B. R. (Forthcoming). "Unpacking team familiarity: The effect of geographic location and hierarchical role." Production and Operations Management.

Staats, B. R. and F. Gino (Forthcoming). "Specialization and variety in repetitive tasks: Evidence from a Japanese bank." Management Sci.

Taylor, F. W. (1911). The Principles of Scientific Management. New York, Harper \& Brothers.

Treasure, T. and S. Gallivan (1999). "On "The learning curve of an academic cardiac surgeon: Use of the CUSUM Method"." Journal of Cardiac Surgery 14(5): 321-322.

Tsikriktsis, N. (2007). "The effect of operational performance and focus on profitability: A longitudinal study of the U.S. airline industry." Manufacturing Service Oper. Management 9(4): 506-517.

Tucker, A. L., I. M. Nembhard and A. C. Edmondson (2007). "Implementing new practices: An empirical study of organizational learning in hospital intensive care units." Management Sci. 53(6): 894907.

Vickers, A. J., F. J. Bianco, A. M. Serio, J. A. Eastham, D. Schrag, E. A. Klein, A. M. Reuther, M. W. Kattan, J. E. Pontes and P. T. Scardino (2007). "The surgical learning curve for prostate cancer control after radical prostatectomy." Journal of the National Cancer Institute 99(15): 1171-1177.

Waldman, J. D., S. A. Yourstone and H. L. Smith (2003). "Learning curves in health care." Health Care Management Review 28(1): 41-54.

Waszak, F., B. Hommel and A. Allport (2003). "Task-switching and long-term priming: Role of episodic stimulus-task bindings in task-shift costs." Cognitive Psych. 46(4): 361-413.

Waszak, F., B. Hommel and A. Allport (2005). "Interaction of task readiness and automatic retrieval in task switching: Negative priming and competitor priming." Memory \& Cognition 33(4): 595-610.

Wylie, G. and A. Allport (2000). "Task switching and the measurement of switch costs." Psych. Research 63: $212-233$. 


\section{Appendix}

Table A-1

List of Patient Controls

\begin{tabular}{l}
\hline Variable \\
\hline Age \\
Race \\
Gender \\
Source of Admission \\
Charlson Score \\
Cerebrovascular Disease \\
Chronic Obstructive Pulmonary Disease \\
Diabetes \\
Diabetes with Sequelae \\
Chronic Renal Failure \\
Incidence of Myocardial Infarction \\
Percutaneous Transluminal Coronary Angioplasty \\
Minimum CABG with Valve \\
Number of Vessels Bypassed \\
Indicator for Type of Valve Repaired / Replaced \\
Use of Left Internal Ascending Mammary \\
\hline Typical complications of sequelae associated with diabetes \\
are retinopathy, neuropathy, nephropathy and arteriosclerosis
\end{tabular}

